\title{
Review article regarding possibilities for speed adjustment at reluctance synchronous motors
}

\author{
Monica Adela Enache, Sorin Enache, Ion Vlad \\ University of Craiova, Faculty of Electrical Engineering, Craiova, Romania \\ Email address: \\ menache@em.ucv.ro (M. A. Enache), senache@em.ucv.ro (S. Enache), ivlad@em.ucv.ro (I. Vlad)
}

\section{To cite this article:}

Monica Adela Enache, Sorin Enache, Ion Vlad. Review Article Regarding Possibilities for Speed Adjustment at Reluctance Synchronous Motors. Journal of Electrical and Electronic Engineering. Vol. 1, No. 4, 2013, pp. 85-89. doi: 10.11648/j.jeee.20130104.14

\begin{abstract}
This paper presents some conclusions of a larger review article which regards possibilities for speed adjustment at synchronous reluctance motors. In the first part there are detailed the command variants by modifying the supply voltage and frequency (open loop control and vectorial control). There are reviewed the variants with and without position sensors. In the second part there is presented the possibility for speed modification by changing the poles number. There is presented a constructive variant of rotor for a reluctance synchronous machine with changing number of poles. The paper ends with conclusions corresponding to the study achieved.
\end{abstract}

Keywords: Reluctance Synchronous Motor, Open Loop Control, Vectorial Control

\section{Introduction}

Owing to multiple possibilities of command developed lately, synchronous reluctance motors are considered a viable alternative to other brushless machines used in industrial application of variable speed [2], [4]-[7], [10]. Starting from this conclusion, this paper aims at mustering a few command possibilities, encountered in the present literature.

As the classical synchronous motors, reluctance synchronous motors develop torque only at synchronism. Consequently, speed adjustment can be ensured, according to known relation for the synchronism speed, by modifying the supply voltage frequency and by changing the number of poles pairs:

$$
\Omega_{1}=2 \pi \frac{f_{1}}{p}
$$

where:

- $\Omega_{1}$, synchronism speed;

- $f_{1}$, the supply voltage frequency;

- $p$, number of poles pairs.

\section{Modifying the Frequency and the Supply Voltage}

There are generally two distinct methods for speed control of drives with reluctance synchronous motors (RSM) supplied by voltage and frequency static converters.

The first and the oldest one consists in achieving a voltage/frequency open loop control. The second one is a method of vectorial control (with field orientation).

\subsection{Open Loop Control}

Open loop control methods were used in '60 years for applications in the field of continuous production processes (packing equipments, glass fabrication etc.) or syntheticfibres twisting, where the reliability and the precise coordination of the speed between a great number of RSM having cage (or permanent magnet motors) supplied by the same six-step inverter were essential.

Figure 1 presents a simplified block scheme of a typical open loop multi-motor drive, with open loop voltage control.

In this system, the shaft speed may be independent on the motor load by ensuring a direct control of the inverter reference with a high stability oscillator.

If weakening field is not required, the RSM operates normally, with a constant ratio U/f (except for the very low speeds, when a supplementary voltage is necessary for compensating RI voltage drops). 
In order to prove that, in the case mentioned above, the synchronizing torque maximum value is constant, the expression of the reactive torque developed by a RSM is taken as a starting point [1]:

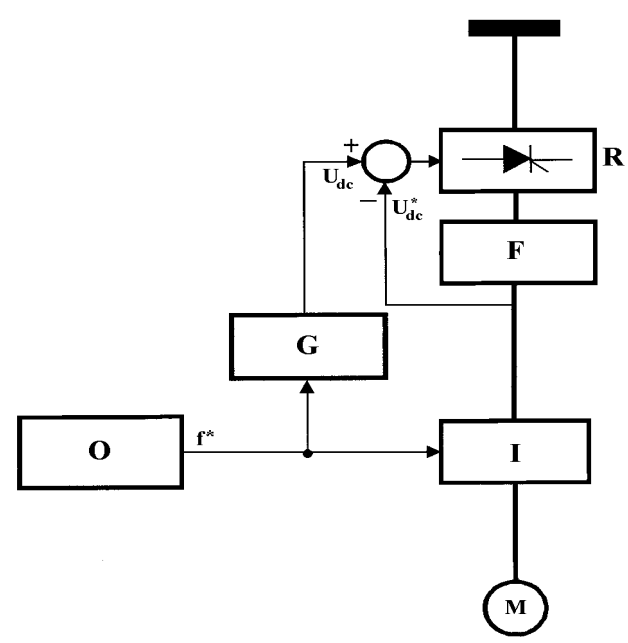

Figure 1. Open loop multi-motor drive: $R$ - rectifier; $F$-filter; $I$-inverter; $O$ - oscillator; $G$ - frequency generator; $M$ - reluctance synchronous motor.

$$
\begin{gathered}
M=\frac{m}{2} \frac{U^{2}}{X_{d} \Omega_{1}} \frac{1-\alpha}{\left(\alpha+\beta^{2}\right)^{2}}\left[\left(\alpha-\beta^{2}\right) \sin 2 \theta-\right. \\
\left.-2 \beta(1+\alpha) \sin ^{2} \theta+2 \alpha \beta\right]
\end{gathered}
$$

where:

- $\mathrm{m}$, number of phases of the stator winding;

- U, supply voltage;

- $\Omega_{1}$, synchronism speed;

- $\theta$, internal angle;

$$
-\alpha=\frac{X_{d}}{X_{q}} ; \beta=\frac{R}{X_{d}},
$$

- Xd, longitudinal synchronous reactance;

- Xq, transversal synchronous reactance;

- R, stator resistance.

Figure 2 presents the phasor diagram of the reluctance synchronous motor.

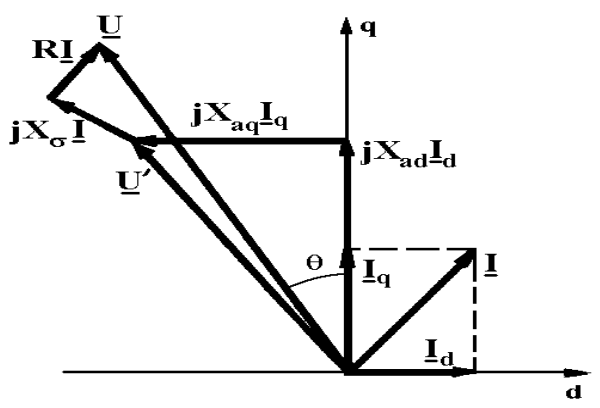

Figure 2. Phasors diagram of RSM [3].
The relation (2) is derived relatively to $\theta$ and forced to be equal to zero.

It is obtained:

$$
\left(\alpha-\beta^{2}\right) \cos 2 \theta_{m}-2 \beta(1+\beta) \sin \theta_{m} \cos \theta_{m}=0,
$$

or, equivalently

$$
\operatorname{tg} 2 \theta_{m}=\frac{\alpha-\beta^{2}}{\beta(1+\alpha)}
$$

In these conditions, the maximum synchronizing torque is given by the relation:

$$
M_{\max }=A \frac{1-\alpha}{\left(\alpha+\beta^{2}\right)^{2}}\left[\sqrt{\left(1+\beta^{2}\right)\left(\alpha^{2}+\beta^{2}\right)}-\beta(1-\alpha)\right]
$$

with

$$
A=\frac{m}{2} \frac{U^{2}}{X_{d} \Omega_{1}} .
$$

The same torque may also be written in the following form:

$$
M_{\max }=\frac{m}{2}\left(\frac{U}{2 \pi f}\right)^{2} \frac{p}{L_{q}}\left(1-\frac{L_{q}}{L_{d}}\right) F_{m}
$$

where

$$
\begin{gathered}
F_{m}=\frac{1}{\frac{L_{q}}{L_{d}}+\left(\frac{R}{2 \pi f L_{d}}\right)^{2}} . \\
\cdot\left\{\sqrt{\left[1+\left(\frac{R}{2 \pi f L_{d}}\right)^{2}\right]\left[\left(\frac{L_{d}}{L_{q}}\right)^{2}+\left(\frac{R}{2 \pi f L_{d}}\right)^{2}\right]}-\frac{R}{2 \pi f L_{d}}\left(1-\frac{L_{d}}{L_{q}}\right)\right\}
\end{gathered}
$$

The six-step inverter hardly provides the sinusoidal supply wanted. The low order current harmonics produced determine important torque pulsations and fluctuating angular speed in case of low velocity.

However, the main source of speed oscillations, at low loads and frequencies belonging to the range of 5-20 Hz, is the inherent instability of RSM. This one can be removed if the machine has a special construction. But this solution is not an economic one and the resultant machine does not have a great asymmetry ratio.

This drawback, together with the delay introduced by a direct current filter (LC), lead to a very slow transient response.

As a consequence, it is possible to conclude that this type of control is only suitable for drives with low dynamic performances.However, drives with open loop RSM are simple and reliable with low inverter losses (because there are only six commutations per cycle).

In order to ensure better dynamic response, it is obviously 
that close loop control methods are necessary. This increase in performance is followed by an increase in the system complexity. Vectorial control is an example of closed loop synchronous motor control and will be addressed in the following section.

\subsection{Vectorial Control}

The main limitations of a drive with open loop RSM can be entirely removed by applying vectorial control. In this framework it is possible to use cageless motors, fed by a current Pulse Width Modulation (PWM) as illustrated in figure 3 [11], [12]. This method is very popular and allows the complete utilization of the great potential of axially laminated RSM (with high asymmetry ratio). Additionally is a viable alternative for asynchronous and for permanent magnet machines in high performances applications.

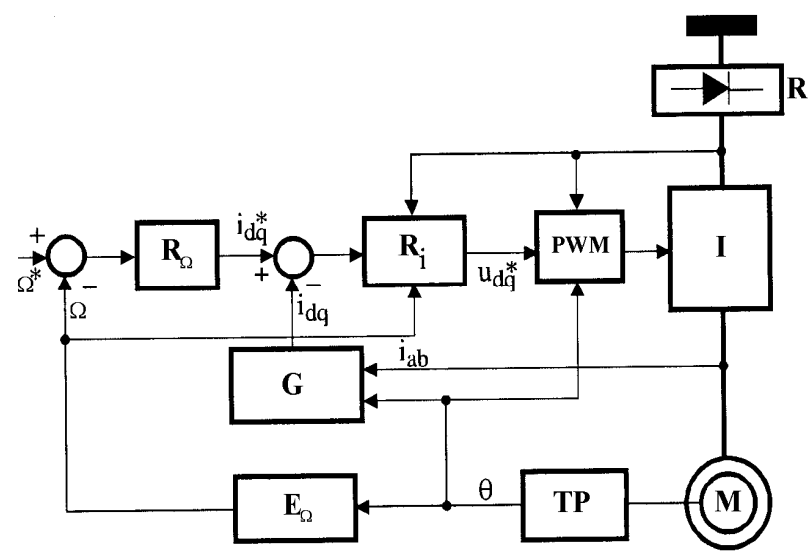

Figure 3. Simplified block scheme of RSM with vectorial command: $R-$ rectifier; $I$ - inverter; $R_{\Omega^{-}}$speed regulator; $R_{i}$ - current regulator; TP position transducer; $E_{\Omega}$ - speed estimator; $M$ - reluctance synchronous motor.

Supplying the motor by a PWM inverter offers important advantages, over the six-step one. Among others the following advantages are enumerated [8]:

- the commutation frequency, for low and average power, can be established out of frequencies that can be heard; thus, the noise problems associated to these drives are avoided;

- it is possible to produce current with almost sinusoidal wave form, with negligible low order harmonics. Hence the fluctuating torques at low speeds and the open loop instability are eliminated;

- the dynamic voltage response is better because the voltage control is achieved by the inverter, in comparison with the previous case where a controlled rectifier was used.

Besides the increased control complexity, there are large losses in both the inverter and the machine due to the high commutation frequency.

By adding fast current control loops and IGBT modulus with commutation frequencies up to $20 \mathrm{kHz}$, the PWM inverter becomes an efficient and reliable current source having a large frequencies band.

The stator resistance effects, very disturbing in RSM drives with open loop command, can now be removed.
Having a good quality supply current control, vectorial control reluctance synchronous motors can satisfy the requirements of high performance servo-mechanisms, such as:

- fast transient answer and smooth torque until it stops;

- high torque and high torque/inertia moment ratio;

- four-quadrant stable operation.

The high commutation speed of the inverter makes possible to get faster dynamic performances in the stator currents command. The simplest approach which is suitable for hardware implementation is based on hysteresis regulators (on/off or "bang-bang") and is often used.

The most complex techniques, involving conventional PI regulators, need explicit width modulation of the pulses (PWM) for voltage. As a consequence, this technique does not have the same fast answer as the hysteresis controllers.

Another drawback of the classical sinusoidal PWM is a greater memory requirement for stocking the search tables containing pre-computed commutation information.

A convenient solution is a PWM based on the utilization of the space vector. This algorithm has a greater modulation index and a lower content of harmonics. Moreover it is more suitable for the software implementation. The pulses width can be directly estimated without being necessary to use the table search.

The increase use of this modulation strategy is determined by the recent developments of special purpose integrated circuits leading to commercial digital modulators designed for operating under the direct control of a microprocessor.

The hardware generation of PWM has the advantage that it reduces the execution time of the real time code and it makes possible a greater control speed. However, if the PWM space vector is used for the current control, the drawback of a poor bandwidth for a current still remains because the current control loop is still implemented by a PI regulator.

The vectorial controllers of RSM operate better in the rotor reference frame in comparison with the stationary reference frame because the sinusoidal variables appear as direct current quantities and they are much easier to be controlled by using classical command techniques.

The command circuit that is usually used is presented in figure 3. This is, in principle, similar with the one used for the indirect field orientation command of an asynchronous machine.

The command algorithm is usually implemented in software written in high level languages (as "C") which then is loaded either on a digital signal processor (DSP) or is run on a personal computer (PC).

An analog hardware design is also possible when a simple and reliable controller is necessary for carrying out the fast dynamic response.

In case of vectorial control, both the RSM and the asynchronous machine behave, from the dynamic view point, as a separately excited direct current machine with close loop command of the armature current.

The fast torque response and the simple command, similar 
to the decoupled command of a direct current machine, can be obtained if the RSM operates in conditions of constant $d$ axis current. The current $i_{d}$ is defined at a value required for establishing the rated air-gap flux, while a fast variation of $i_{q}$ is responsible for the torque variations and for the system dynamics.

\subsubsection{Sensorless Command}

Recently there have been carried out significant progresses and there have been developed several method for RSM, without using rotor position sensors.

Although it is true that RSM is more suitable for sensorless operation, in comparison with an asynchronous machine due to its inherent asymmetry, the experience has proved that this objective is not easily achieved [8].

These treatments have some limits:

- they omit the saturation effects;

- they are not sensitive to the parameters inaccuracy.

This approach does not have these drawbacks in the case of the independent upon parameters ones. It either does not need information about the rotor position or it involves more complicated techniques (and therefore more complex) for detecting the position which is independent on load or on the machine parameters modification.

However, both approaches regarding the command strategies use the same fundamental principle connected with the variation of the self and mutual inductances of the stator windings at the same time with the rotor position.

\subsubsection{Command Based on Position Sensors Utilization}

The renewed interest for RSM, which started at the end of the ' 80 years, has led to the publication of an important number of papers about different aspects regarding RSM command and performances.

These ones can be mainly divided up into three groups.

The first group of papers is connected by establishing of the performance limits and by the command techniques for the optimal operation of the ideal RSM (without saturation and without losses). The papers from the second group take into consideration the saturation and the stator iron losses impact on the RSM behaviour and on the command performances.

The main command objective of the third group of papers was to improve the dynamic performances including only the saturation in the RSM model.

\section{Changing the Number Pole}

As it is known, the step modification of the alternating current motors speed can be obtained by changing simultaneously the poles number on both stator and rotor. This command method may be achieved relatively easily at squirrel cage asynchronous motors where it is enough to modify the number of poles pairs for the stator winding. The situation is not the same at asynchronous motors having phase-wound rotor and at classical synchronous motors where the speed adjustment by such methods involves very special problems.

In case of reluctance synchronous motors this adjustment method needs the use of some rotors having special configurations. For example, figure 4 presents a rotor allowing the pole number modification from 4 to 6 [9].

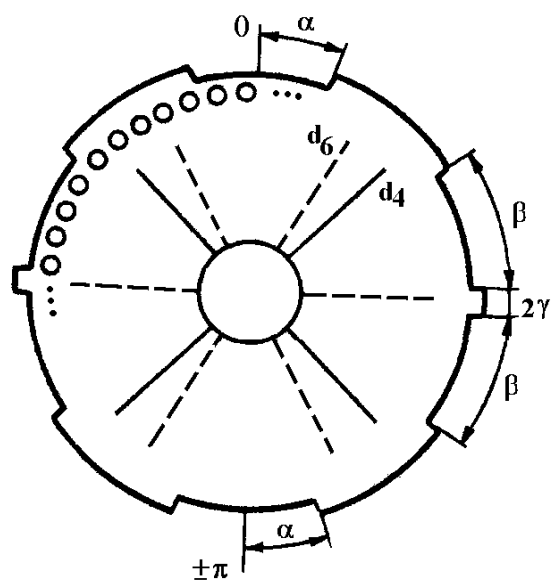

Figure 4. Simplified section through a rotor having two steps of speed.

The permeance variation form in this case is presented in figure 5 .
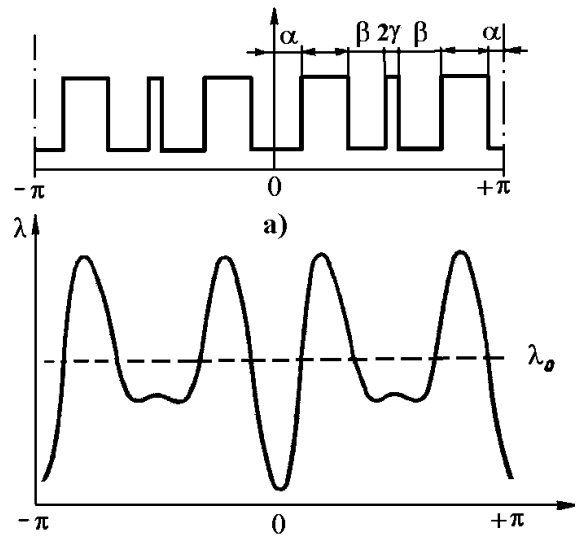

b)

Figure 5. Developed rotor (a) and permeance variation (b) for the considered synchronous motor.

When the excitation field has four poles, the synchronous torque is produced by the fourth harmonic of the permeance, while the effect of the sixth harmonic is a null average torque On the other hand, when the excitation field has six poles, the fourth harmonic of the permeance produces a null average torque, while the sixth harmonic generates the active synchronous torque. Motors with three or four speeds have been built by starting from this principle, but the obtained performances have not justified their utilization in industry on a large scale.

\section{Conclusions}

From the above presentation the following conclusions are provided: 
1. The sensorless command of RSM has become popular in the latest 15 - 20 years. The reason for using his command is connected with the elimination of the fragile position sensor from drive.

Fortunately, the inherent asymmetry of the RSM makes it suitable for sensorless operation. The price which is paid for the low costs and for the reliability of sensorless drive is that the command performances are usually compromised and a more complicated design of the controller is necessary.

2. The real-time sensorless command is not easy. Until now only a few authors was being capable of this achievement.

The major contribution of their work has been the development of some viable techniques for the position estimation irrespective of the machine parameters and of the operation point. A part of the proposed command algorithms have the advantage that they make possible to obtain a satisfactory command of the shaft speed in all range. Other algorithms are applicable either at low speed, or at high speed.

The sensorless command schemes have also a few drawbacks:

- a relatively poor precision for the position estimation;

- a low estimations updating speed and, consequently, poor command performances ;

- the use of some special commutation procedures for forcing the inverter in a specific state in order to achieve significant measurements;

- the injection of some special high frequency signals which must be filtered in order to obtain the position estimation.

3. The review of the literature about the RSM command on the basis of the position sensors utilization clearly shows that the most recent researches are focussed on the development of the optimal command strategies using an ideal model or a saturated model, with negligible iron losses. The reason of this option is, undoubtedly, to obtain a simpler command when the iron losses resistor misses in the $\mathrm{d}-\mathrm{q}$ schemes.

The researches regarding the command based on the real model of the machine, when considering both the saturation and the iron losses, are very important.

However, few papers regarding this theme have emerged and only a few of them contain real-time implementations of such a strategy. Therefore, it is expected that the efforts of the future researches to be focussed towards this direction.

\section{References}

[1] Betz, R.E.: Theoretical Aspects of Control of Synchronous Reluctance Machines, Proc. IEE, Vol. B-139, n. 4, 1992, pp. 355-364.

[2] Cheok, A.D., Fukuda, Y.: A new torque and flux control method for switched reluctance motor drives, IEEE Transactions on Power Electronics, Volume 17, Issue 4, 2002, ISSN 0885-8993, pp. $543-557$.

[3] Campeanu, A., Cautil, I., Vlad, I., Enache, S.: Modelling and simulating alternating current electrical machines, Romanian Academy Publishing House, Bucharest, 2012, ISBN 978-973-27-2233-6.

[4] Enache, M.A., Enache, S., Dobriceanu, M.: Considerations regarding dynamic regimes of reluctance synchronous motors, 19-th International Symposium on Power Electronics, Electrical Drives, Automation and Motion SPEEDAM 2008, Ischia (Italy), 11-13 June, , pp. 284-289.

[5] Enache, M. A., Campeanu, A., Enache, S., Vlad, I.: Possibilities for reluctance synchronous machines parameters experimental determination, Anals of the University of Craiova, Series Electrical Engineering, Year 36, No. 36, 2012, ISSN 1842-4805, pp. 176-181.

[6] Enache, S., Campeanu, A., Vlad, I.; Enache, M. A.: Possibility for analysis of the reluctance synchronous motors dynamic stability, Advanced Topics in Electrical Engineering (ATEE), 7th International Symposium, 2011, pp. 1-6.

[7] Enache, S., Campeanu, A., Vlad, I., Enache, M. A.: Reluctance synchronous motors modelling and analysis, Anals of the University of Craiova, Series Electrical Engineering, Year 36, No. 36, 2012, ISSN 1842-4805, pp. 170-175.

[8] Jovanovic, M.G, Ahmed, M.M.R.: Sensorless Speed Control Strategy for Brushless Double Fed Reluctance Machines, Electric Machines \& Drives Conference, 2007, IEMDC '07, 3-5 May 2007, pp. 1514.

[9] Magureanu, R., Vasile, N. Permanent magnet and reluctance synchronous motors, Technical Publishing House, Bucharest, 1982.

[10] McCann, R.A., Islam, M.S.; Husain, I.: Application of a sliding-mode observer for position and speed estimation in switched reluctance motor drives, IEEE Transactions on Industry Applications, Volume 37, Issue 1, ISSN: 0093-9994, pp. 51-58.

[11] Vas, P.: Sensorless Vector and Direct Torque Control, Oxford University Press, 1998.

[12] Vas, P.: Vector Control of AC Machines, Clarendon Press, 1990. 